\title{
How the Hippies Destroyed the Internet
}

W HEN WE REFER to "the Internet" we refer not only to the global system of interconnected computer networks but also to the set of applications that utilize this network, including email, the Web, search engines, social media, and the like. To understand where this Internet comes from, we have to revisit the emergence of online communities in the early and mid-1980s. Consider, for example, the WELL, which began in 1985 as a dial-up bulletin board system, self-described as "a cherished watering hole for articulate and playful thinkers." One of its founders was Stewart Brand, best known as editor of the Whole Earth Catalog, an American counterculture magazine and product catalog published periodically since the late 1960s. "Counterculture" refers to a late1960s-early-1970s Western antiestablishment cultural movement, whose members were known as "hippies." Today's Internet, with its techno-utopian culture, ${ }^{\text {a }}$ connects with the 1960 s counterculture movement.

In a 1984 Hackers' Conference, Brand told Steve Wozniak, a founder of Apple Inc., "Information wants to be free, because the cost of getting it out is getting lower and lower all the time." This phrase, "Information wants to free," came to mean people should be able to access information freely. It has become an ideology of many technology activists who criticize any restriction to open and free access to information. Completely forgotten today is the fact that this phrase is taken out of context; the preceding sentence by Brand was "Information wants to be expensive, because it's so valuable." Of course, infor-

a https://bit.ly/2GyQ0XP mation does not want anything. It is people who want information to be free, but "Information wants to be free" meshed well with the antiestablishment character of the techno-utopianism. When the Internet and the World-Wide Web grew explosively in the early 1990s, information freedom became a mantra.

But information freedom meant that rather than creating an information market, information has become "commons," an unregulated shared public resource, which, as popularized by Garrett Hardin in an influential 1968 article, is subject to "The Tragedy of the Commons." This phrase refers to the phenomenon where individual users acting independently according to their own self-interest behave contrary to the common good. Of course, we all love free information. The question is whether information freedom is good for society.

But markets in which the prices for goods and services are determined by sellers and buyers are among the greatest inventions of human civilization, though arguments continue about the relative advantages and disadvantages of free markets, coordinated markets, regulated markets, and the like. Regardless of the details, markets provide us with a mechanism for finding the value of goods and services. Communism is the most famous $20^{\text {th }}$-century attempt to build market-free economies. It required coercion on a colossal scale, with an incalculable cost in human lives. The Internet is the second major attempt to build a market-free economy, limited to information. When search and social emerged as business in the late 1990s and mid-2000s, respectively, information freedom was already a hallowed Internet principle, and companies have adapted to it by making themselves into advertising companies. Ethan Zuckerman, director of the MIT Center for Civic Media, called information freedom "The original sin of the Internet."b

Why is information freedom such a horrible mistake? To start with, information freedom is, of course, an illusion. Google and Facebook are stupendously profitable companies. Where do these profits come from? "Not from me," you may say, "the advertisers pay to advertise." But advertising is just the cost of doing business, and advertisers simply pass the cost of advertising to the price of the goods and services they provide. Thus, instead of having a transparent market in which posted prices lead to value discovery, we have an opaque market in which consumers support Internet companies via, essentially, an invisible tax.

But market opaqueness is just one problem. As we now know, Internet advertisers require data to ensure effective delivery of ads, so we not only pay for "free information" with invisible tax, we pay for it also with our personal information. The Internet has become a huge surveillance machine.

In a recent New York Magazine article, the "Internet apologized." The article contains a breakdown of what went wrong with the Internet from the architects who built it. It is worth reading. But the real question is whether it is not too late to ditch the ad-based business model and build a better Internet. This is, I believe, one of the most important questions in computing right now! c

\footnotetext{
b https://theatln.tc/2wU5Xsa

c https://slct.al/2GZ6hGr
}

Moshe Y. Vardi (vardi@cs.rice.edu) is the Karen Ostrum George Distinguished Service Professor in Computational Engineering and Director of the Ken Kennedy Institute for Information Technology at Rice University, Houston, TX, USA $\mathrm{He}$ is the former Editor-in-Chief of Communications.

Copyright held by author. 